\title{
Synthesis and Magnetic Properties of a Highly Conducting Neutral Nickel Complex with Highly Conjugated Tetrathiafulvalene Dithiolate Ligand
}

\author{
He-Rui Wen, ${ }^{\dagger}$ Cheng-Hui Li, ${ }^{\dagger}$ You Song, ${ }^{\dagger}$ Jing-Lin Zuo,,${ }^{\dagger}$ Bin \\ Zhang, ${ }^{*},{ }^{\ddagger}$ and Xiao-Zeng You ${ }^{\dagger}$ \\ Coordination Chemistry Institute and the State Key Laboratory of Coordination \\ Chemistry, School of Chemistry and Chemical Engineering, Nanjing University, \\ Nanjing 210093, China, and Organic Solid Laboratory, CMS, Institute of Chemistry, \\ Beijing 100080, China
}

\section{Supporting materials}

\section{Synthesis}

The synthetic procedure is shown in Scheme 1. The ligand precursor, 2,3-bis(2-cyanoethylthio)-benzotetrathiafulvalene, was prepared according to previous reported literature method. ${ }^{1}$ The cyanoethyl group was removed by using $\mathrm{Me}_{4} \mathrm{NOH}$ as the base in THF generating the dithiolate. The dithiolate ligand reacted further with nickel(II) ions and resulted in the metal complex, $\left(\mathrm{Me}_{4} \mathrm{~N}\right)_{0.8}\left[\mathrm{Ni}(\mathrm{btdt})_{2}\right](\mathbf{1})$. The pure neutral complex, $\left[\mathrm{Ni}(\mathrm{btdt})_{2}\right](\mathbf{2})$, was obtained either by an oxidative reaction with 1 and $I_{2}$ or by electrochemical method. 


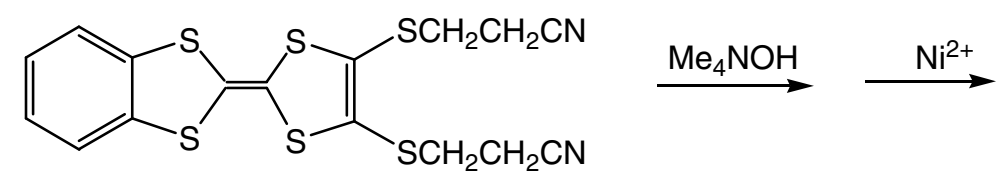<smiles>CO[N+](C)(C)CCc1ccc2c(c1)SC(=C1SC3=C(S1)S[N+]1(SC4=C(SC(=C5Sc6ccccc6S5)S4)S1)S3)S2</smiles>

1

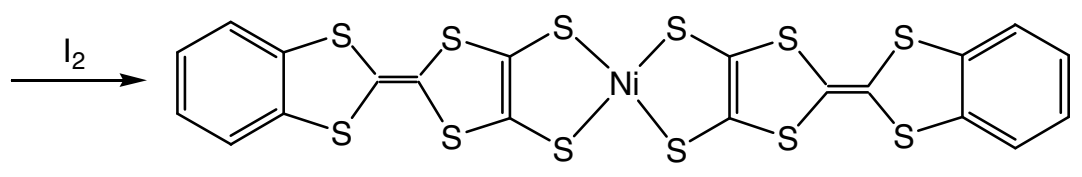

2

Scheme 1. The synthetic procedure for the nickel complex [Ni(btdt $\left.)_{2}\right](\mathbf{2})$.

$\left(\mathrm{Me}_{4} \mathrm{~N}\right)_{0.8}\left[\mathrm{Ni}(\mathrm{btdt})_{2}\right]$ (1): Under a nitrogen atmosphere, a methanol solution of $\mathrm{Me}_{4} \mathrm{NOH} \quad(0.45 \mathrm{ml}, 25 \% \quad(\mathrm{w} / \mathrm{w}), \quad 1 \mathrm{mmol})$ was added to 2, 3-bis(2-cyanoethylthio)-benzotetrathiafulvalene (212 $\mathrm{mg}, 0.5 \mathrm{mmol})$ in $20 \mathrm{ml}$ of THF at $-5{ }^{\circ} \mathrm{C}$. The reaction mixture was stirred at this temperature for $30 \mathrm{~min}$. THF was removed in vacuo and the resulting orange solid was dissolved in methanol. $\mathrm{NiCl}_{2} \cdot 6 \mathrm{H}_{2} \mathrm{O}(60 \mathrm{mg}, 0.25 \mathrm{mmol})$ in methanol was added and the reaction mixture was left to stir overnight. The resulting brown powder was collected by filtration, washed with methanol and ether, and dried in vacuo. Yield: 84.6\%. Anal. calcd for $\mathrm{C}_{23.2} \mathrm{H}_{17.6} \mathrm{~N}_{0.8} \mathrm{~S}_{12} \mathrm{Ni}$ : C, 37.12; H, 2.35; N, 1.49; S, 51.20; Ni, 7.83. Found: C, 37.15; H, 2.45; N, 1.38; S, 50.96; Ni, 7.95. IR (v/cm $\left.{ }^{-1}\right): 3425,3013,1585,1567,1486,1445$, $1433,1312,1266,1118,1059,1020,947,770,739,674,469$.

[Ni(btdt $)_{2}$ ] (2): Complex $1(150 \mathrm{mg}, 0.20 \mathrm{mmol})$ was dissolved in $20 \mathrm{ml}$ of DMF under nitrogen. Iodine $(77 \mathrm{mg}, 0.30 \mathrm{mmol}$ ) was added and the reaction mixture was stirred at room temperature for $10 \mathrm{~h}$. The precipitate was filtered off, washed with acetonitrile, methanol and ether, dried in vacuo. A brown-black powder was obtained. The solid in $15 \mathrm{ml}$ of toluene was sealed in a $20 \mathrm{ml}$ stainless-steel reactor with a Teflon liner and heated at $120{ }^{\circ} \mathrm{C}$ for 15 days. Finally the resulting product was dried. Yield: $85 \%$. Anal. calcd for $\mathrm{C}_{20} \mathrm{H}_{8} \mathrm{~S}_{12} \mathrm{Ni}$ : C, 34.76; H, 1.15; S, 55.60; Ni, 8.50. Found: 
C, 34.78; H, 0.93; S, 55.37; Ni, 8.41. IR (v/cm $\left.{ }^{-1}\right): 1561,1464,1430,1349,1232$, 1046, 953, 776, 731, 672, 461.

\section{Structure Determination by Powder X-ray Diffraction}

a) Sample preparation and data collection: To increase the crystallinity, $300 \mathrm{mg}$ of [Ni(btdt $\left.)_{2}\right]$ in $15 \mathrm{ml}$ of toluene was sealed in a $20 \mathrm{ml}$ stainless-steel reactor with a Teflon liner and heated at $120{ }^{\circ} \mathrm{C}$ for 15 days. The resulting solid was dried and mechanically ground into fine powders. The fine powder was side-loaded onto a glass holder for data collection. Step-scanned X-ray powder diffraction data were collected using Bruker D8 Advance $\theta / \theta$ diffractometer with parallel $\mathrm{CuK} \alpha(\lambda=1.5406 \AA$, rated as $1.6 \mathrm{~kW}$ ) X-ray radiation via the Göbel mirror. After a preliminary data collection, the mounted sample was unpacked and reloaded onto the sample holder to minimize the systematic errors from the particle statistics and preferred orientation of the solids. The sample crystallinity has much improvement after solvent-thermal treatment, but is still unsatisfactory. Data collection parameters: $2 \theta$ range $=3-60^{\circ}$, step size $=0.02^{\circ}$, speed of scan $=5$ second/step. Reproducible dataset of each sample was obtained and the sample damage by prolonged X-ray irradiation was negligible.

b) Structure solution: Only 15 distinct peaks were found in the powder pattern of $\left[\mathrm{Ni}(\mathrm{btdt})_{2}\right]$ due to the poor crystallinity. These peaks were used for indexing with DICVOL04 ${ }^{2}$. A triclinic unit cell $[a=6.6102 \AA, b=7.2322 \AA, c=12.8340 \AA, \alpha=$ $89.58^{\circ}, \beta=93.03^{\circ}, \gamma=112.311^{\circ}, V=566.767 \AA^{3} . M(15)=17.3, F(15)=14.8(0.0094$, 86)] was found. These $P \overline{1}$ unit cell were then used for the following process since: i) attempts to index the powder pattern with higher symmetry lattice were unsuccessful; ii) the high occurrence of $P \overline{1}$ lattice in the analogous compound ([Ni(tmdt) $\left.)_{2}\right]$ and [Ni(hfdt $\left.\left.)_{2}\right]\right)$. According to the unit cell volumes, a half of formula mass units of [Ni(btdt $\left.)_{2}\right]$ was used per asymmetric unit. The models of $\left[\mathrm{Ni}(\mathrm{btdt})_{2}\right]$ were built and written as a MOL file format by the program GaussView $3.0^{3}$ and later were converted to sets of fractional coordinates written in a Z-MARTIX file format by program Babel or OPENBABEL. ${ }^{4}$ Bond distances and bond angles were used 
according to the single crystal structure of $\left[\mathrm{Ni}(\mathrm{tmdt})_{2}\right]$. All the atoms were constrained into a plane. The positions of aromatic hydrogen atoms were added onto their parent carbon atoms in the idealized geometry.

Structure solutions calculations of $\left[\mathrm{Ni}(\mathrm{btdt})_{2}\right]$ were initiated by a global optimization of experimental diffraction profiles using parallel tempering approach implemented in the program FOX..$^{5}$ A large number of trial structures were calculated using default parameters/setting. Selected structure solutions were examined and judged based on educated chemical and physical knowledge as well as the graphical fit between the calculated and experimental diffractographs.

c) Structure refinement: Prior to any structural refinement, the chemically sensible structure solution was manually adjusted so as to remove those unrealistic close non-bonded contacts by applying the appropriate sets of bond distance and bond angle restraints. For instance, when those bad contacts were disappeared then the corresponding weighing factors of those distance restraints were reduced accordingly. The model adjustment process was repeated many times until there are no overlapped atoms or unrealistic bad contacts for non-bonded atoms. Subsequent Rietveld profile refinement by the full matrix least squares was carried out by GSAS/EXPGUI ${ }^{6}$ suite programs. Scattering factors, corrected for real and imaginary anomalous dispersion terms were taken form the internal library of GSAS. Overall scale factor and the coefficients of the linear interpolation background function were refined. Profile shape parameters (Pseudo-Voigt function) ${ }^{7}$ instrumental parameters $(\mathrm{S} / \mathrm{L})$ and $(\mathrm{H} / \mathrm{L})$, sample displacement (shft) and sample transparency (trns), Gaussian peak width (GW) and the Lorentzian peak broadening factor due to the microstrain effect of crystallites (LY) were sequentially refined. When the refinement of all these non-structural parameters became converged with a negligible (shift/esd) ${ }^{2}$ value, the model-biased profile refinement was switched in which the unit cell parameters $(a, b, c$ and $\beta)$, atomic coordinates, background, peak profile parameters were refined together to give the final $R_{p}, R_{w p}, R_{\text {exp }}$ and $R_{F}$ factors $\left(R_{p}=0.0843, R_{W P}=0.1253, R_{F}=0.0824, R_{\text {exp }}=\right.$ 0.0658). Figure S1 shows the final Rietveld refinement plot. The satisfactory, but still imperfect match between observed and calculated data is mostly attributed to the 
irregular background cause by poor crystallinity.

d) Crystal structure description: The crystal structure of $\left[\mathrm{Ni}(\mathrm{btdt})_{2}\right]$ determined from powder diffraction data is similar to other single-component molecular metals such as $\left[\mathrm{Ni}(\mathrm{tmdt})_{2}\right],\left[\mathrm{Ni}\left(\mathrm{C}_{10} \mathrm{H}_{10} \mathrm{~S}_{8}\right)_{2}\right],\left[\mathrm{Ni}(\mathrm{ptdt})_{2}\right]$ and $\left[\mathrm{Ni}(\mathrm{hfdt})_{2}\right]$. The [Ni(btdt $\left.)_{2}\right]$ molecule is ideally planar (Figure $\mathrm{S} 2$ ). $\pi \cdots \pi$ interactions were observed between the terminal phenyl groups (Figure S3). Neighboring molecules are closely packed in the crystal plane (111) (Figures S4 and S5).

There is a crucial difference in molecular packing between $\left[\mathrm{Ni}(\mathrm{btdt})_{2}\right]$ and $\left[\mathrm{Ni}(\mathrm{tmdt})_{2}\right]$. In [Ni(btdt $\left.)_{2}\right]$, all the neighboring molecules are in slipped stacking along the shorter molecular axis. But for $\left[\mathrm{Ni}(\mathrm{tmdt})_{2}\right]$, the neighboring molecules are somewhat "dimerized" and form a zig-zag columnar structure along the stacking direction. In fact, we have ever found a trial structure during structure solution which presents the same molecular arrangement with $\left[\mathrm{Ni}(\mathrm{tmdt})_{2}\right]$. However, this structure candidate has to be abandoned since the simulated X-ray powder diffraction pattern is completely different with that observed in our experiment even when the preferential orientation has been considered (Figure S6).

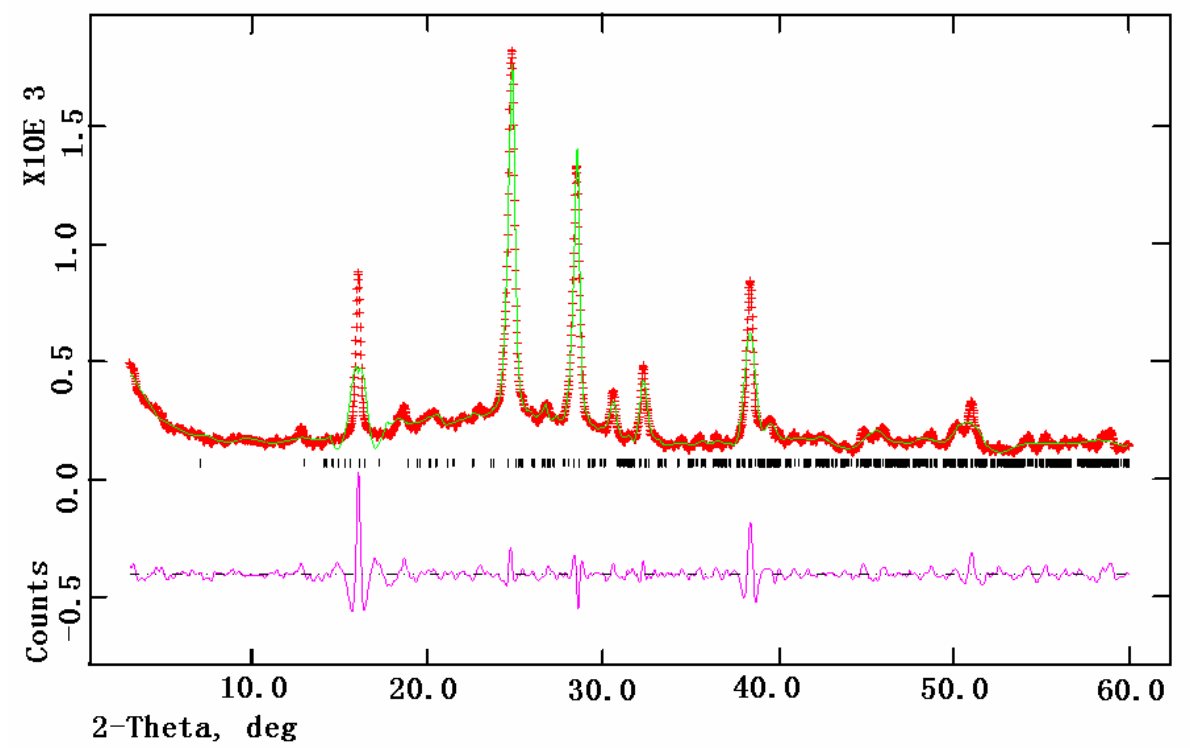

Figure S1. Graphical plots of the final Rietveld refinement cycle for [Ni(btdt) ${ }_{2}$ (red crossed signs $=$ observed data points, green line $=$ calculated profile, vertical ticks $=$ Bragg peak positions). The difference plot (magenta) between the experimental and calculated powder diffraction profile is shown at the bottom of each plot. 


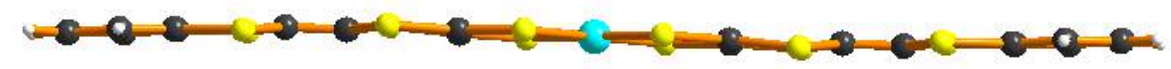

a)

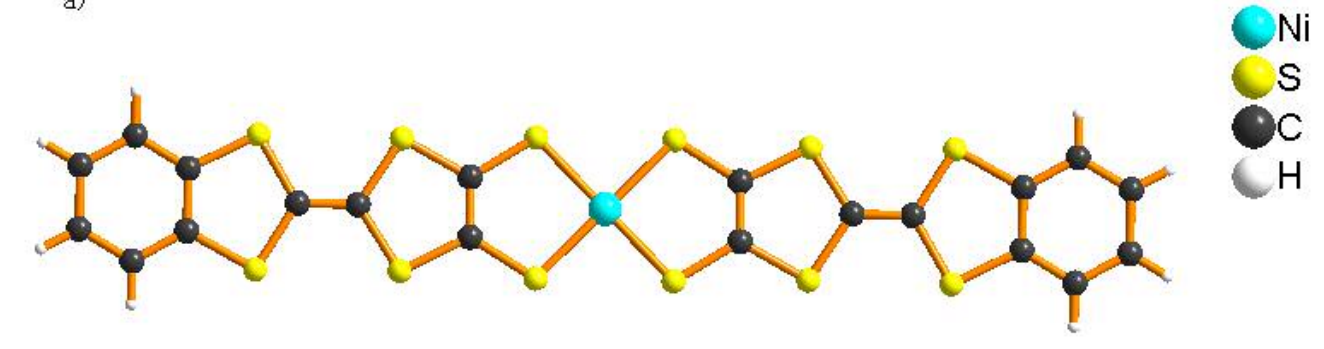

b)

Figure S2. a) Crystal structure of complex $\left[\mathrm{Ni}(\mathrm{btdt})_{2}\right]$. b) Side view.

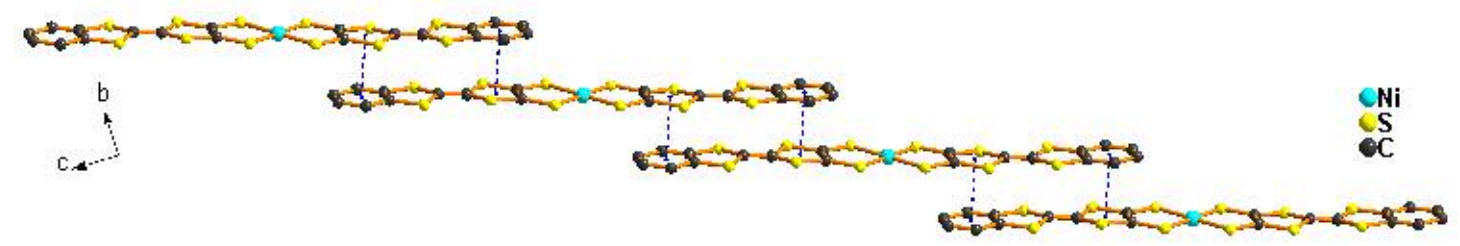

Figure S3. Schematic representation (dashed lines) of the intermolecular $\pi-\pi$ stacking interactions of complex [Ni(btdt $\left.)_{2}\right]$.

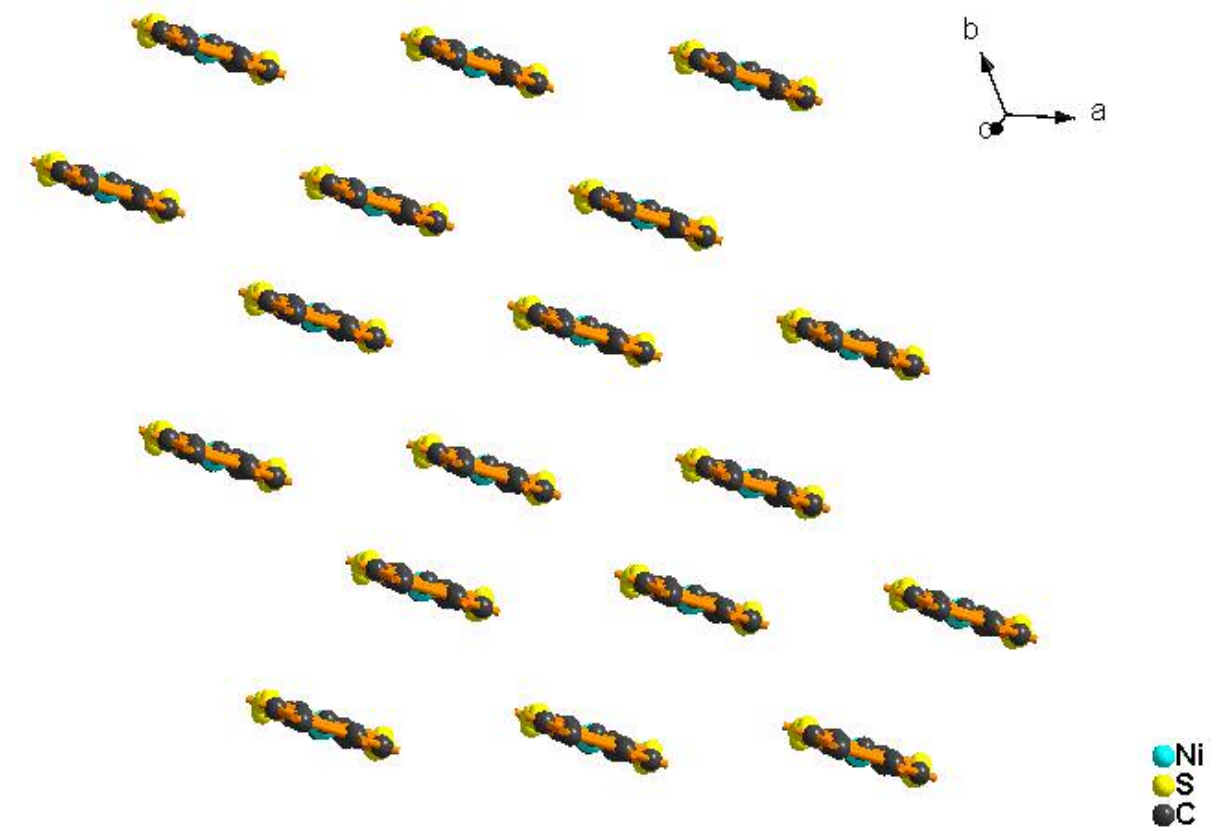

Figure S4. Crystal packing diagram view along [111] direction 


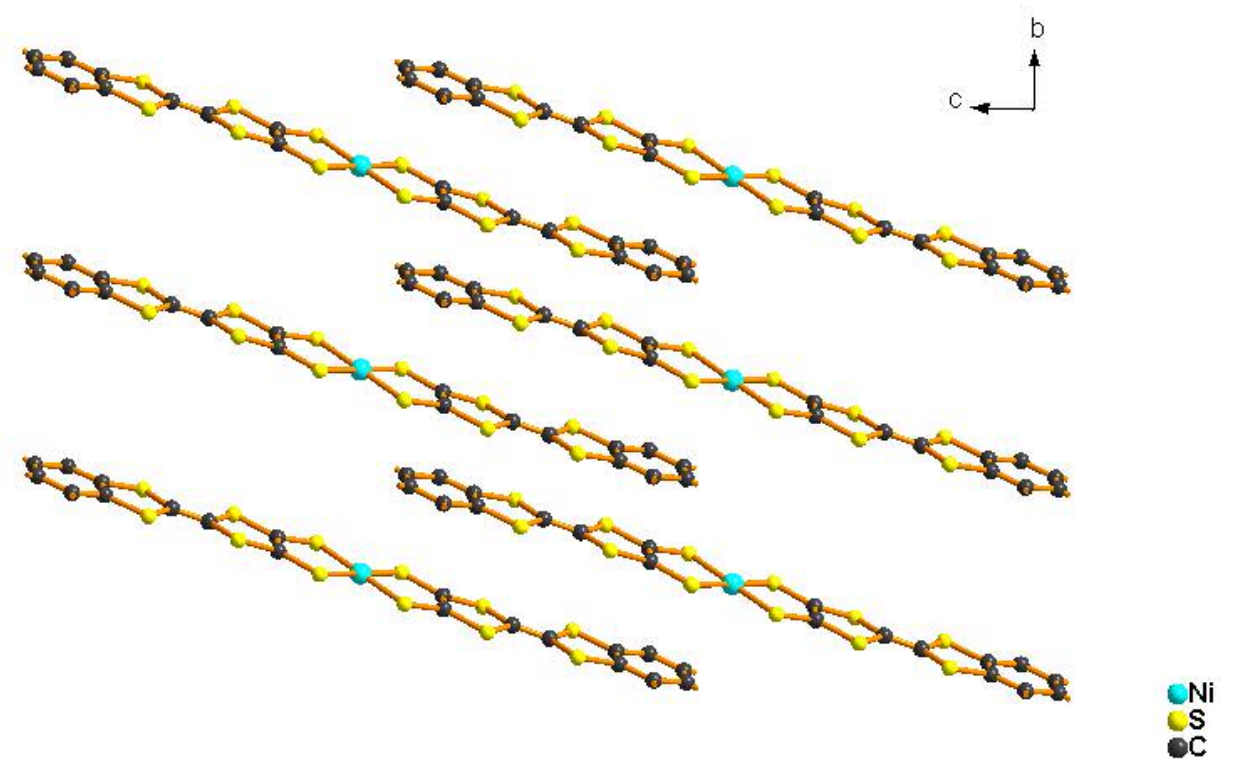

Figure S5. Crystal packing diagram view along the $a$ axis

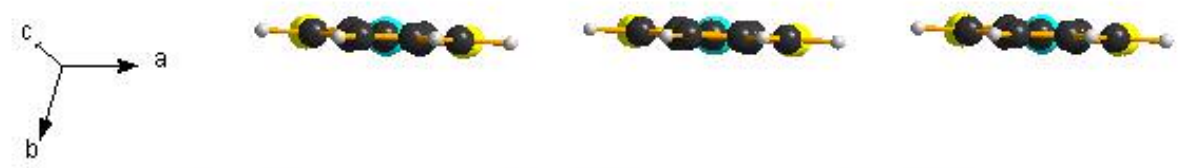

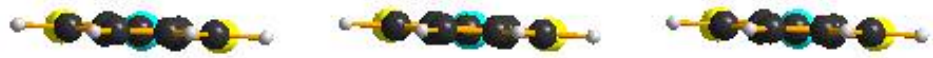

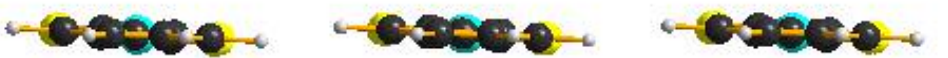




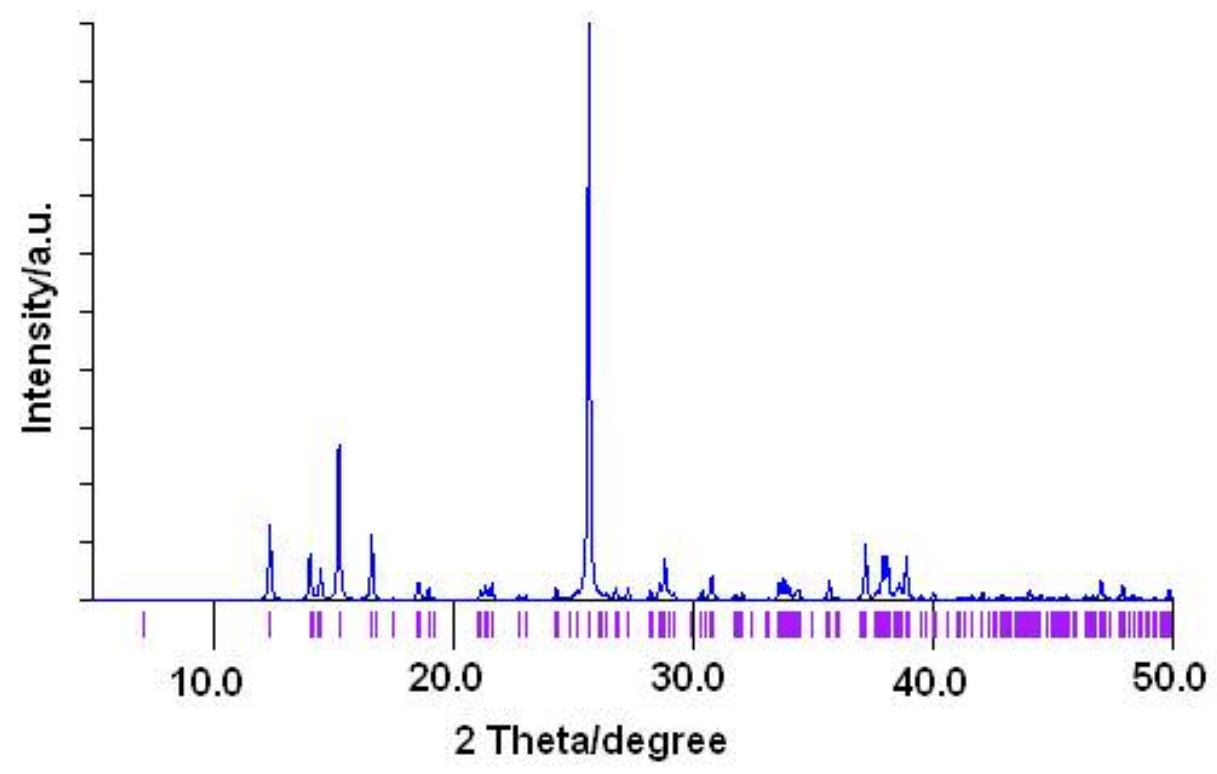

b)

Figure S6. Crystal packing diagram and simulated X-ray powder diffraction pattern of a trial structure which has the same molecular arrangement with $\left[\mathrm{Ni}(\mathrm{tmdt})_{2}\right]$.

\section{Physical Property Measurements}

Electrical conductivities were measured on compressed pellets by using a four-probe method at various temperatures between 80-300 K. Magnetic susceptibility measurements for sample $\left[\mathrm{Ni}(\mathrm{btdt})_{2}\right]$ were obtained with the use of a Quantum Design MPMS-XL7 SQUID magnetometer at temperatures ranging from 1.8-300 K. The dc measurements were collected from -70 to $70 \mathrm{kOe}$. Data were corrected for the diamagnetic contribution calculated from Pascal constants. 


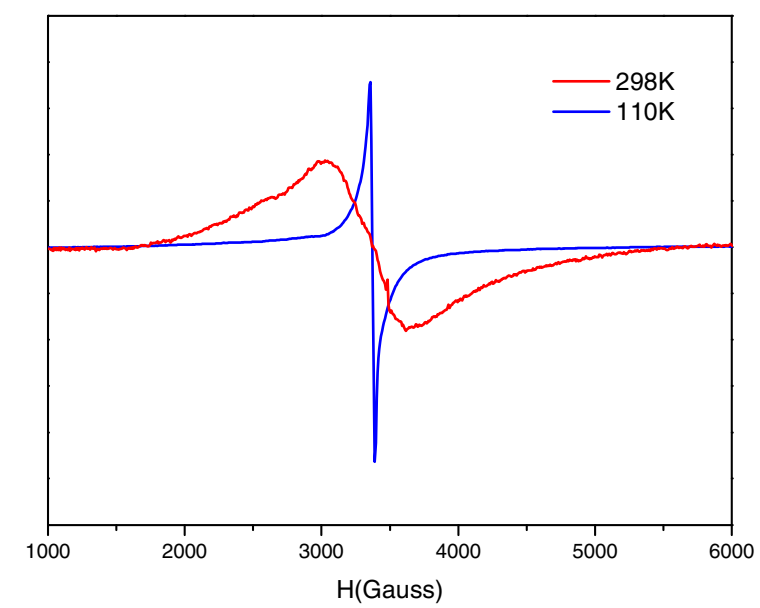

Figure S7. ESR spectra of [Ni(btdt $\left.)_{2}\right]$ in solid state at 298 and $110 \mathrm{~K}$.

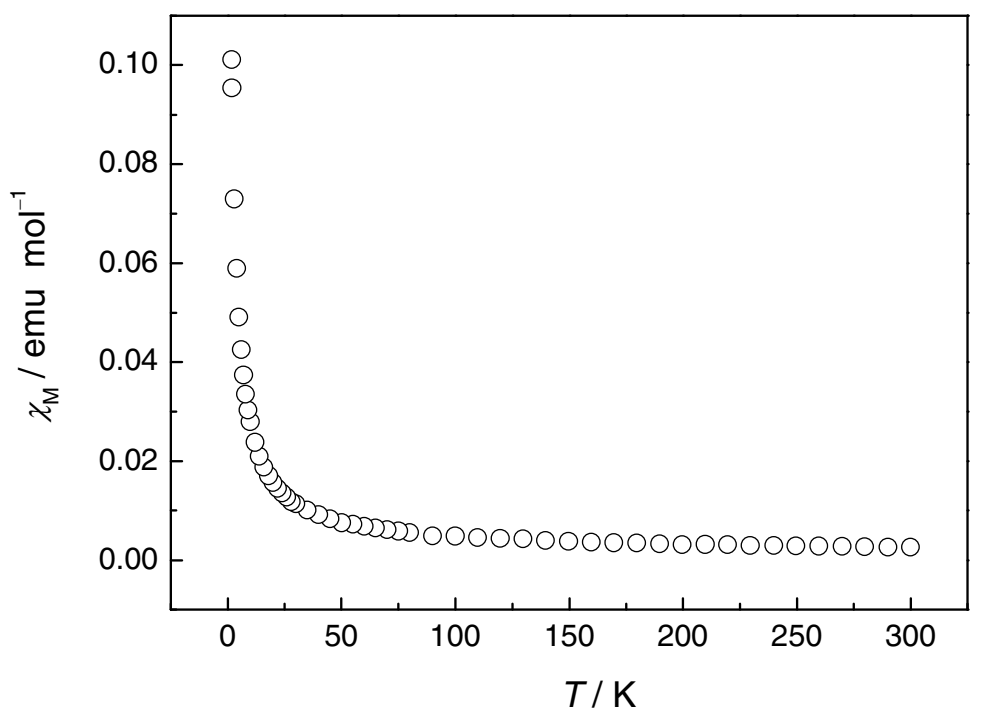

Figure S8. Temperature dependence of the magnetic susceptibility of [Ni(btdt $\left.)_{2}\right]$.

\section{Molecular orbital calculations}

Calculations on the electronic structure of $\left[\mathrm{Ni}(\mathrm{btdt})_{2}\right]$ were carried out under both local density approximation (LDA) and generalized gradient approximation (GGA). The SVP and 6-31g(d,p) basis sets augmented in the GAUSSIAN03 program was used. The starting atomic coordinates were used from the crystal structure. All calculations were performed using the GAUSSIAN03 program package. ${ }^{8}$ 
The optimized structure has a good planarity and has approximately a $D_{2 h}$ point group for $\left[\mathrm{Ni}(\mathrm{btdt})_{2}\right]$. The HOMO (highest occupied molecular orbital) and LUMO (lowest unoccupied molecular orbital) are $\pi$-like orbitals with $b_{3 u}$ and $b_{2 g}$ symmetries, respectively. The schematic drawings of the HOMO and LUMO orbitals are shown in Figure S9. The HOMO has a nodal plane at the central Ni atom. Unlike to other neutral nickel complex with highly conjugated tetrathiafulvalene dithiolate ligand, where the HOMO has nothing to do with the terminal groups, the HOMO of complex $\left[\mathrm{Ni}(\mathrm{btdt})_{2}\right]$ has small contribution from the $\mathrm{C}$ atoms of the phenyl group. The LUMO has a small contribution from the d orbital of the central Ni atom. The HOMO-LUMO gap is estimated to be $0.405-0.478 \mathrm{eV}$.

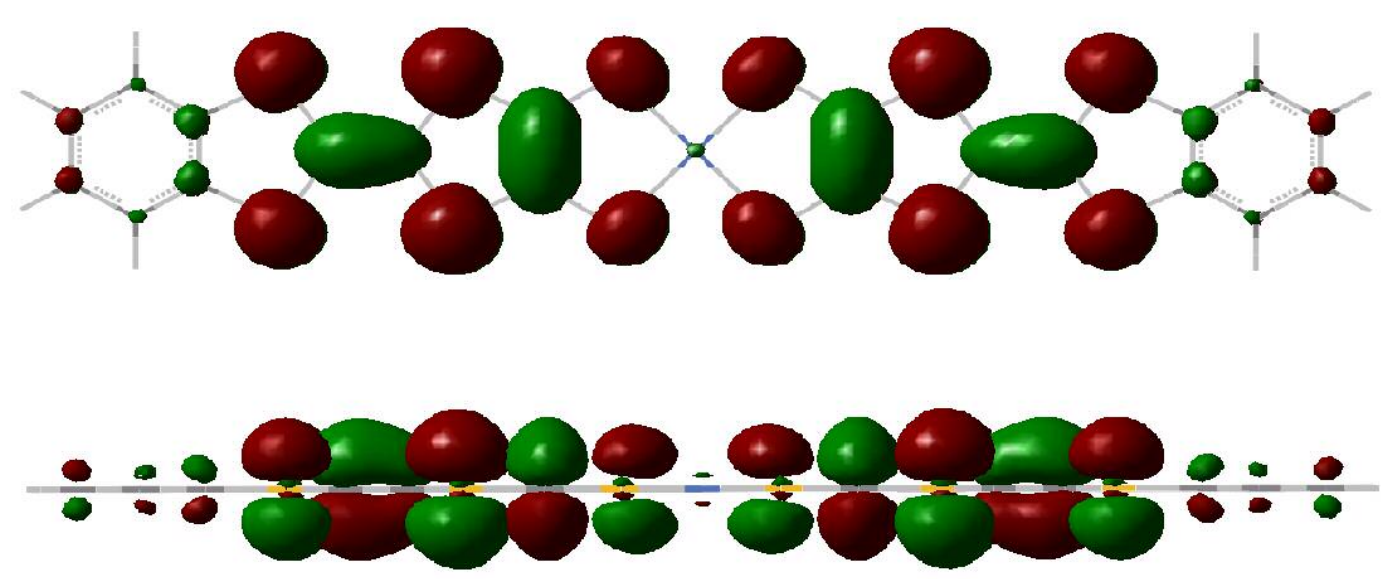

a) HOMO
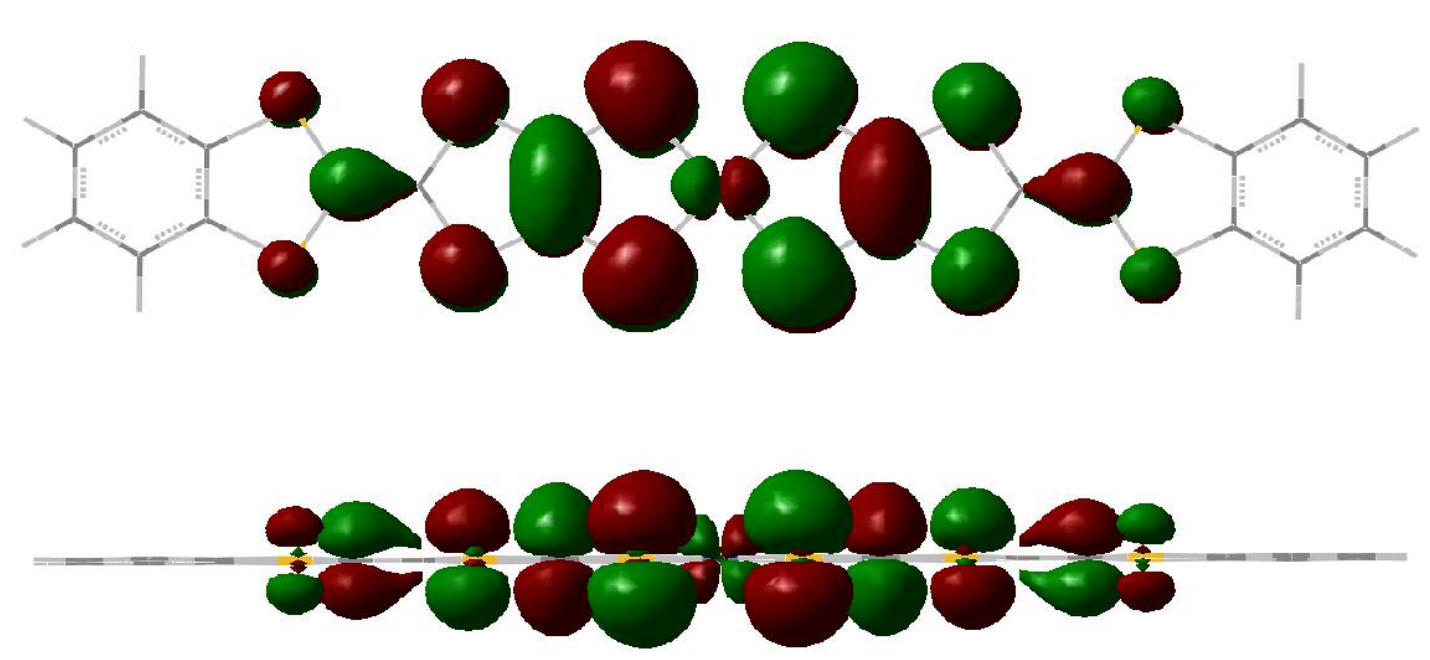

b) LUMO

Figure S9. Schematic drawings of the HOMO and LUMO of [Ni(btdt $\left.)_{2}\right]$. 
Calculation on the lowest triplet state shows that little is changed after a charge transition in this system. The HOMO-LUMO energy gap $(0.244-0.509 \mathrm{eV})$ is sensitive to the method being used but it generally close to that of the ground state. The energy difference between the ground state and the lowest triplet state is very small $(\Delta \mathrm{E}($ Triplet $)-\Delta \mathrm{E}($ Singlet $)=0.332-0.494 \mathrm{eV})$.

The electronic structure of $\left[\mathrm{Ni}(\mathrm{tmdt})_{2}\right]$ was also calculated for comparison. Table S1 shows the HOMO-LUMO (both in ground state and the lowest triplet state) and Singlet-Triplet energy gap for $\left[\mathrm{Ni}(\mathrm{btdt})_{2}\right]$ and $\left[\mathrm{Ni}(\mathrm{tmdt})_{2}\right]$. It is noteworthy that there is little difference between $\left[\mathrm{Ni}(\mathrm{btdt})_{2}\right]$ and $\left[\mathrm{Ni}(\mathrm{tmdt})_{2}\right]$ no mater what the method is being used. These results clearly suggest that the molecular packing mode, rather than HOMO-LUMO energy gap, plays a key role in determining the electrical property.

Table S1. Calculated HOMO-LUMO and Triplet-Singlet energy gap for [Ni(btdt $)_{2}$ ] and $\left[\mathrm{Ni}(\mathrm{tmdt})_{2}\right]$.

\begin{tabular}{|c|c|c|c|c|c|c|c|}
\hline & \multicolumn{3}{|c|}{$\left[\mathrm{Ni}(\mathrm{btdt})_{2}\right]$} & \multicolumn{3}{|c|}{$\left[\mathrm{Ni}(\mathrm{tmdt})_{2}\right]$} \\
\hline & & \multicolumn{2}{|c|}{$\Delta \mathrm{E}_{1}(\mathrm{eV})$} & \multirow{2}{*}{$\begin{array}{l}\Delta \mathrm{E}_{2} \\
(\mathrm{eV})\end{array}$} & \multicolumn{2}{|c|}{$\Delta \mathrm{E}_{1}(\mathrm{eV})$} & \multirow{2}{*}{$\begin{array}{l}\Delta \mathrm{E}_{2} \\
(\mathrm{eV})\end{array}$} \\
\hline & & Singlet & Triplet & & Singlet & Triplet & \\
\hline \multirow[t]{2}{*}{ LDSA } & SVP & 0.465 & 0.455 & 0.461 & 0.420 & 0.428 & 0.424 \\
\hline & $6-31 \mathrm{~g}(\mathrm{~d}, \mathrm{p})$ & 0.478 & 0.509 & 0.494 & 0.430 & 0.479 & 0.452 \\
\hline \multirow[t]{2}{*}{ BLYP } & SVP & 0.405 & 0.244 & 0.332 & 0.371 & 0.232 & 0.309 \\
\hline & $6-31 \mathrm{~g}(\mathrm{~d}, \mathrm{p})$ & 0.419 & 0.284 & 0.358 & 0.382 & 0.268 & 0.330 \\
\hline
\end{tabular}

$* \Delta \mathrm{E} 1=\Delta \mathrm{E}($ Lumo $)-\Delta \mathrm{E}($ номо $)(\mathrm{eV}) ; \Delta \mathrm{E} 2=\Delta \mathrm{E}($ Triplet $)-\Delta \mathrm{E}($ Singlet $)(\mathrm{eV})$

\section{Extended Hückel Tight-binding Calculations}

To understand the difference of conductivity between $\left[\mathrm{Ni}(\mathrm{btdt})_{2}\right]$ and $\left[\mathrm{Ni}(\mathrm{tmdt})_{2}\right]$, Extended Hückel tight-binding calculations (EHTB) were performed. As deduced from the molecular orbital calculation, the molecular packing mode may play a key role for their electrical properties. We calculated the band structure of $\left[\mathrm{Ni}(\mathrm{btdt})_{2}\right]$ on two types of packing mode as show in Figure 2. The final crystal structure of $\left[\mathrm{Ni}(\mathrm{btdt})_{2}\right]$ and the trial structure of $\left[\mathrm{Ni}(\mathrm{btdt})_{2}\right]$ (Figure S6) were used as the models 
for stack a) and stack b) respectively. But these models are slightly modified to ensure that they only differ in the packing modes. The bond lengths and angles are set to the same value within these two models. The vertical distances between neighboring molecules along the stacking direction and the distances between neighboring molecules along the shorter molecular axis were kept constant. These modifications are accomplished by the program GSAS/EXPGUI ${ }^{6}$ by using restraint and/or constraint. The PC version of CAESAR program ${ }^{9}$ was used for the calculations. Atomic parameters adopted in the calculations are shown in Table S2.

Table S2. Atomic Parameters used in EHTB Calculations ${ }^{a}$ : Valence orbital Ionization Potential $\mathrm{H}_{\mathrm{ii}}(\mathrm{eV})$ and Exponent of the Slater-type Orbital $\zeta$

\begin{tabular}{|l|l|l|l|l|}
\hline Atom & Orbital & \multicolumn{1}{|c|}{$\mathrm{H}_{\mathrm{ii}}$} & \multicolumn{1}{|c|}{$\zeta_{1}$} & $\zeta_{2}$ \\
\hline $\mathrm{Ni}$ & $4 \mathrm{~s}$ & -9.17 & 1.825 & \\
& $4 \mathrm{p}$ & -5.15 & 1.125 & \\
& $3 \mathrm{~d}$ & -13.49 & $5.75(0.5683)$ & $2.0(0.6292)$ \\
$\mathrm{S}$ & $3 \mathrm{~s}$ & -20.0 & 2.122 & \\
& $3 \mathrm{p}$ & -13.3 & 1.827 & \\
$\mathrm{C}$ & $2 \mathrm{~s}$ & -21.4 & 1.625 & \\
& $2 \mathrm{p}$ & -11.4 & 1.625 & \\
$\mathrm{H}$ & $1 \mathrm{~s}$ & -13.6 & 1.3 & \\
\hline
\end{tabular}

${ }^{a}$ These parameters are augmented in CAESAR program as Double zeta (collected).

For stacking a), the HOMO and LUMO bandwidths were estimated to be are 0.266 and $0.198 \mathrm{eV}$, respectively. Figure S10a) shows the band dispersion curves. There is no overlap between the HOMO and LUMO bands. Only very small electron and hole pockets were obtained on the Fermi surface. This result is consistent with the observed semi-conducting property of $\left[\mathrm{Ni}(\mathrm{btdt})_{2}\right]$.

However, when the $\left[\mathrm{Ni}(\mathrm{btdt})_{2}\right]$ molecules are packed like $\left[\mathrm{Ni}(\mathrm{tmdt})_{2}\right]$ (stacking b)), the calculated HOMO and LUMO bandwidths were 0.291 and $0.262 \mathrm{eV}$ respectively. The two bandwidths had an overlap of $0.06 \mathrm{eV}$ (Figure 10b)). Large electron and hole pockets were obtained on the Fermi surface. This situation is similar to that of $\left[\mathrm{Ni}(\mathrm{btdt})_{2}\right]$. 

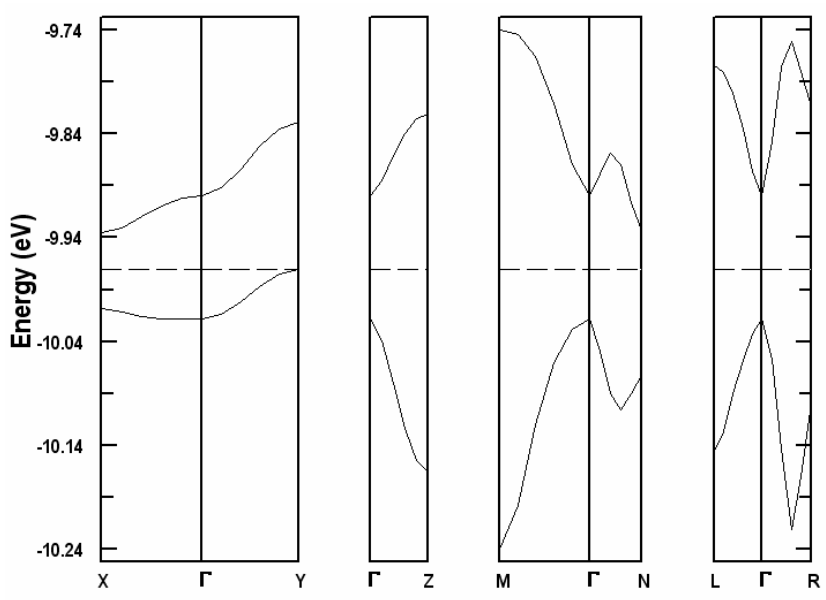

a)
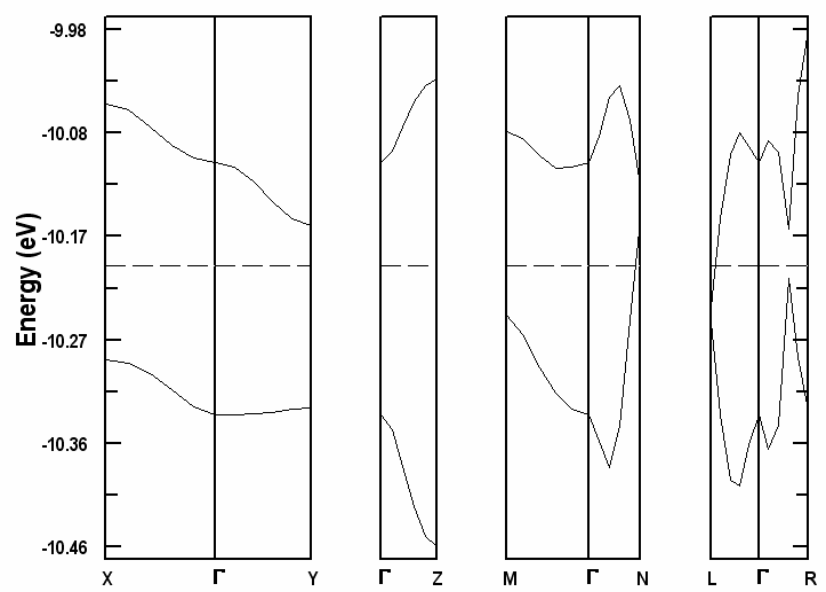

b)

Figure S10. Band energy dispersion curves of $\left[\mathrm{Ni}(\mathrm{btdt})_{2}\right]$ in two packing mode where the dashed line refers to the Fermi level. $\Gamma=(0,0,0), \mathrm{X}=(1 / 2,0,0), \mathrm{Y}=(0,1 / 2,0), \mathrm{Z}=$ $(0,0,1 / 2), M=(1 / 2,1 / 2,0), N=(1 / 2,0,1 / 2), L=(0,1 / 2,1 / 2)$, and $\mathrm{R}=(1 / 2,1 / 2,1 / 2)$, in units of the triclinic reciprocal lattice vectors.

\section{References:}

(1) Wen, H. R.; Zuo, J. L.; Scott, T. A.; Zhou, H. C.; You, X. Z. Polyhedron, 2005, 24, $671-677$.

(2) Boultif, A.; Löuer, D. J. Appl. Crystallogr. 2004, 37, 724-731.

(3) Gaussview 03, Pittsburgh PA: Semichem Inc, Gaussian, 2003.

(4) Babel: $\quad$ http://www.eyeopen.com/babel/);

OPENBABEL:

http://openbabel.sourceforge.net

(5) Favre-Nicolin, V.; Cerný, R. J. Appl. Crystallogr. 2002, 35, 734-743. FOX, "free objects for crystallography”: A modular approach to ab initio structure 
determination from powder diffraction.

(6) Larson, A. C.; Von Dreele, R. B. "General Structure Analysis System (GSAS)", Los Alamos National Laboratory Report LAUR 86-748 2004; Toby, B. H. EXPGUI, A Graphical User Interface for GSAS, J. Appl. Crystallogr. 2001, 34, 210-221.

(7) Thompson, P.; Cox, D. E.; Hastings, J. B. J. Appl. Crystallogr. 1987, 20, 79-83; Finger, L. W.; Cox, D. E.; Jephcoat, A. P. J. Appl. Crystallogr. 1994, 27, 892-900

(8) Gaussian 03, Revision C.02, Frisch, M. J.; Trucks, G. W.; Schlegel, H. B.; Scuseria, G. E.; Robb, M. A.; Cheeseman, J. R.; Montgomery Jr., J. A.; Vreven, T.; Kudin, K. N.; Burant, J. C.; Millam, J. M.; Iyengar, S. S.; Tomasi, J.; Barone, V.; Mennucci, B.; Cossi, M.; Scalmani, G.; Rega, N.; Petersson, G. A.; Nakatsuji, H.; Hada, M.; Ehara, M.; Toyota, K.; Fukuda, R.; Hasegawa, J.; Ishida, M.; Nakajima, T.; Honda, Y.; Kitao, O.; Nakai, H.; Klene, M.; Li, X.; Knox, J. E.; Hratchian, H. P.; Cross, J. B.; Adamo, C.; Jaramillo, J.; Gomperts, R.; Stratmann, R. E.; Yazyev, O.; Austin, A. J.; Cammi, R.; Pomelli, C.; Ochterski, J. W.; Ayala, P. Y.; Morokuma, K.; Voth, G. A.; Salvador, P.; Dannenberg, J. J.; Zakrzewski, V. G.; Dapprich, S.; Daniels, A. D.; Strain, M. C.; Farkas, O.; Malick, D. K.; Rabuck, A. D.; Raghavachari, K.; Foresman, J. B.; Ortiz, J. V.; Cui, Q.; Baboul, A. G.; Clifford, S.; Cioslowski, J.; Stefanov, B. B.; Liu, G.; Liashenko, A.; Piskorz, P.; Komaromi, I.; Martin, R. L.; Fox, D. J.; Keith, T.; Al-Laham, M. A.; Peng, C. Y.; Nanayakkara, A.; Challacombe, M.; Gill, P. M. W.; Johnson, B.; Chen, W.; Wong, M. W.; Gonzalez, C.; Pople, J. A., Gaussian, Inc., Pittsburgh PA, 2003.

(9) Ren, J.; Liang, W.; Whangbo, M. H. Crystal and Electronic Structure Analysis Using CAESAR, 1998, PrimeColor Software, Inc. 